\title{
Subcellular Fractionation by Differential and Zonal Centrifugation of the Trypanosomatid Crithidia fasciculata
}

\author{
By CLIVE EDWARDS* AND DAVID LLOYD \\ Department of Microbiology, University College, Cardiff CF2 ITA
}

(Received 17 December 1976)

\begin{abstract}
SUMMARY
Homogenates of Crithidia fasciculata were fractionated by differential centrifugation. Mitochondria were sedimented quantitatively at ${ }^{1} 0^{4} \mathrm{~g}$-min and accounted for approximately 10\% of the total recovered protein. Catalase was found exclusively in the supernatant fraction whilst NADH: cytochrome $c$ oxidoreductase and $p$-nitrophenylphosphatase were found in all the fractions. Zonal centrifugation confirmed that catalase was non-sedimentable. Clean separation of mitochondria was obtained in both high-speed and rate zonal experiments, but no NADH:cytochrome $c$ oxidoreductase activity could be detected in these organelles. Separation of large lysosomal vacuoles which contained $p$-nitrophenylphosphatase activity was obtained and these were clearly resolved from mitochondria by both highspeed and rate zonal centrifugation.
\end{abstract}

\section{INTRODUCTION}

Satisfactory analytical subcellular fractionation studies of trypanosomes have not been reported, mainly due to the resistance of these parasites to conventional cell disruption methods (Simpson, 1972) which may be due to the presence of pellicular microtubules (Angelopoulos, 1970). Previous studies with Crithidia fasciculata used relatively harsh cell breakage methods, such as a French pressure cell or sonication (Toner \& Weber, 1967), grinding with alumina (Hill \& White, 1968) or using a Polytron blender after treatment with digitonin (Kusel \& Storey, 1972). Such methods have mainly been used in an attempt to isolate intact mitochondria from trypanosomes, a task made difficult as the organism contains a single large mitochondrion which convolutes and branches throughout the cytoplasm.

In the present investigation we have achieved good separation of subcellular organelles by density-gradient zonal centrifugation of cell-free homogenates prepared by rupturing digitonin-treated suspensions of $C$. fasciculata in a Chaikoff press.

\section{METHODS}

Growth, harvesting and preparation of cell-free extracts. Crithidia fasciculata was maintained, grown, counted, harvested and disrupted as previously described (Edwards \& Lloyd, I973).

Fractionation of whole homogenates by differential centrifugation. The whole homogenate was centrifuged for $10 \mathrm{~min}$ at $10000 \mathrm{~g}\left(r_{\mathrm{av} .}=7.6 \mathrm{~cm}\right)$ in the $8 \times 50 \mathrm{ml}$ rotor of an MSE I 8 centrifuge. The supernatant fluid (SI) was carefully decanted, leaving the first pellet (PI), and then centrifuged for $20 \mathrm{~min}$ at $20000 \mathrm{~g}$ in the same centrifuge. This supernatant fluid (S2) was decanted from the first 'microsomal' pellet $\left(\mathrm{P}_{2}\right)$ and centrifuged for $60 \mathrm{~min}$ at

\footnotetext{
* Present address: Department of Microbiology, University of Liverpool, Liverpool L69 3BX.
} 
$106000 \mathrm{~g}\left(r_{\mathrm{av}} .=6 \mathrm{~cm}\right)$ in the $8 \times 10 \mathrm{ml}$ rotor of an MSE 40 centrifuge, giving a pellet $\left(\mathrm{P}_{3}\right)$ and a final supernatant fluid $\left(\mathrm{S}_{3}\right)$. The pellets were uniformly resuspended in known volumes of the homogenization buffer immediately on collection. All procedures were carried out at $4{ }^{\circ} \mathrm{C}$.

Fractionation by zonal centrifugation. High-speed zonal centrifugation was done in a BXIV rotor (Anderson et al., I967) in an MSE 40 centrifuge. The rotor was loaded at 2500 rev. $\mathrm{min}^{-1}$ with a linear sucrose gradient $[15$ to $60 \%(\mathrm{w} / \mathrm{w})$, total vol. $400 \mathrm{ml}$, the remainder of the rotor being filled with $60 \%(\mathrm{w} / \mathrm{w})$ sucrose. The whole homogenate was pumped into the centre of the rotor followed by $30 \mathrm{ml}$ of $6 \%(\mathrm{w} / \mathrm{w})$ sucrose, and then $30 \mathrm{ml}$ of $4 \%(\mathrm{w} / \mathrm{w})$ sucrose overlay. The rotor was accelerated to $35000 \mathrm{rev} . \mathrm{min}^{-1}$ for $165 \mathrm{~min}\left(6 \times 10^{6} \mathrm{~g}\right.$-min at the sample zone). The rotor was unloaded at $2500 \mathrm{rev} . \mathrm{min}^{-1}$ and fractions (Io $\mathrm{ml}$ ) were collected at $4{ }^{\circ} \mathrm{C}$. Rate zonal centrifugation was done in an MSE HS zonal rotor in an MSE 18 centrifuge. The procedure was identical to that for high-speed zonal centrifugation except that the rotor was loaded and unloaded at $600 \mathrm{rev} . \mathrm{min}^{-1}$ and was accelerated to $10000 \mathrm{rev}$. $\mathrm{min}^{-1}$ for $30 \mathrm{~min}$. All sucrose solutions used for zonal centrifugation in rotors contained $2 \mathrm{mM}^{-} \mathrm{MgCl}_{2}$ and were buffered to $\mathrm{pH} 8.0$ with $\mathrm{Io} \mathrm{mm}-\mathrm{Tris} / \mathrm{HCl}$. The gradients were generated and loaded into the rotor using an Isco 'Dialagrad' Pump (Shandon Southern Instruments, Camberley, Surrey) at a flow rate of 15 to $30 \mathrm{ml} \mathrm{min}{ }^{-1}$. Sucrose concentrations were measured using a refractometer and densities were calculated from the data of De Duve, Berthet \& Beaufay (1959).

Enzyme assays. Assay conditions for acid p-nitrophenylphosphatase (EC 3.1.3.2), catalase (EC I . I I I .6), NADH: cytochrome $c$ oxidoreductase (EC I .6.99.3) and NADPH: cytochrome $c$ oxidoreductase (EC I 6.2.4) have been described previously (Lloyd et al., I97I). $\beta$-Glucosidase (EC 3.2 I . 2I) was assayed as described by Gatt (I969). Methods used for malate dehydrogenase (EC I.I.I.37), succinate:cytochrome $c$ oxidoreductase (EC I.3.99.I) and succinate dehydrogenase (EC I.3.99.I) were as described by Poole \& Lloyd (1973). Assays for acid p-nitrophenylphosphatase were performed at $25^{\circ} \mathrm{C}$, and all spectrophotometric assays were carried out at room temperature (I $8 \pm 2{ }^{\circ} \mathrm{C}$ ) using a Cary model 14 recording spectrophotometer fitted with a fine slide wire which gave a full-scale deflexion corresponding to an extinction of $0 \cdot r$.

Other determinations. Protein was measured by the method of Lowry et al. (195I) with bovine serum albumin as standard. Electron micrographs were obtained as described by Cartledge \& Lloyd (1972).

Chemicals. All enzyme substrates were obtained from Sigma. Bovine serum albumin (fraction V from bovine plasma) was from Armour Pharmaceuticals, Eastbourne, Sussex.

Treatment and presentation of results. Enzyme units are expressed as nmol substrate transformed $\mathrm{min}^{-1}$ or nmol product formed $\mathrm{min}^{-1}$. The vertical lines in Figs 2 and 3 divide the diagrams at density intervals of $0.05 \mathrm{~g} \mathrm{ml}^{-1}$. Percentage sedimentability in high-speed zonal centrifugation experiments is arbitrarily expressed as that proportion of total enzyme units recovered which had sedimented at densities greater than $\mathrm{I} \cdot \mathrm{I} O \mathrm{~g} \mathrm{~m} \mathbf{~ m}^{-1}$ after centrifuging for $6 \times 10^{6} \mathrm{~g}$-min.

\section{RESULTS}

Changes in specific activities of enzymes during growth

Specific activities of all the enzymes assayed were at a maximum in homogenates of organisms harvested after 40 to $48 \mathrm{~h}$, which corresponded to the late-exponential phase of growth and a density of approximately $1 \cdot 5 \times 10^{8}$ organisms $\mathrm{ml}^{-1}$ (Fig. I). All experiments were performed with organisms from this phase of growth. 


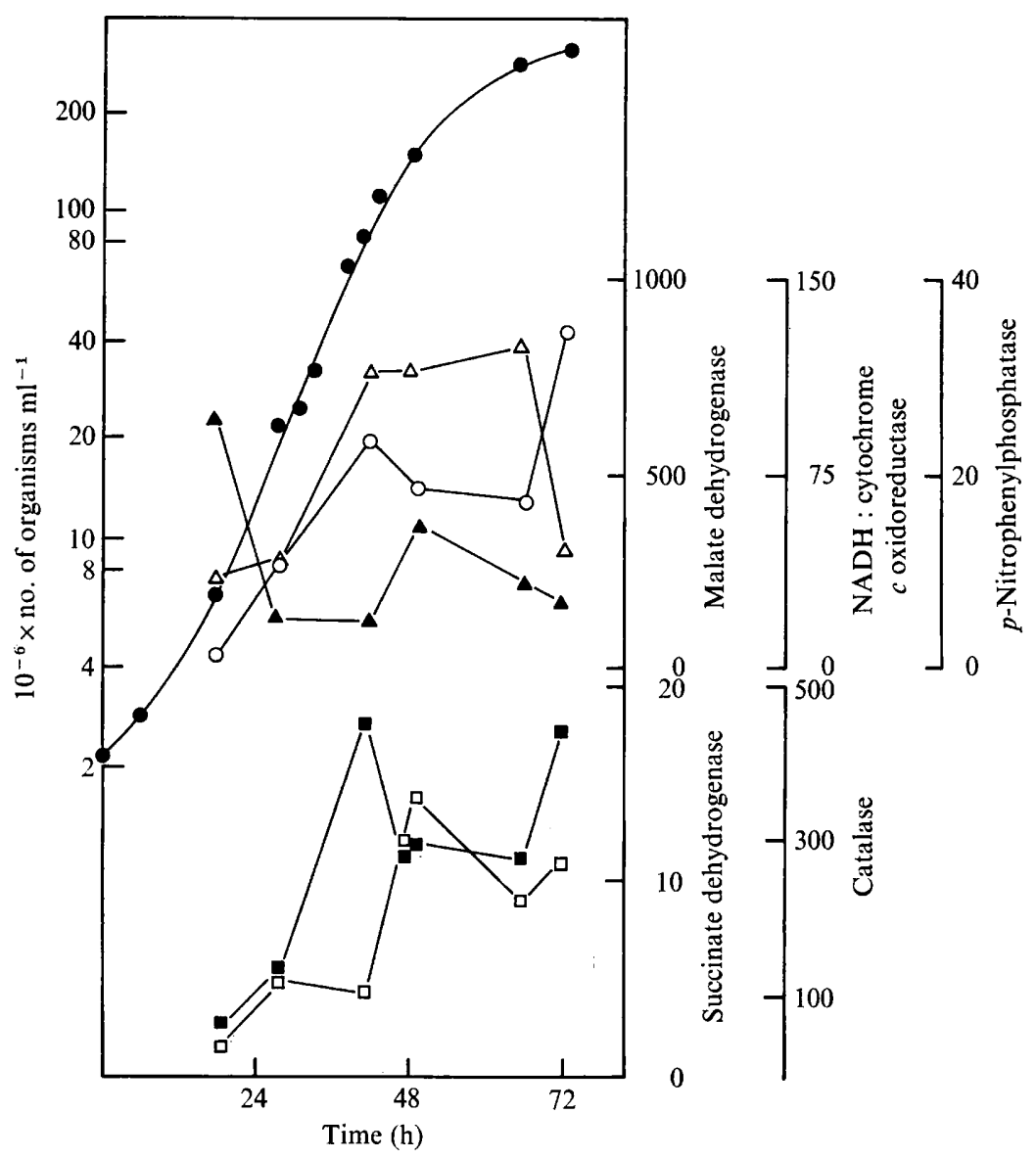

Fig. I. Changes in the specific activities of malate dehydrogenase $(\triangle), N A D H$ : cytochrome $c$ oxidoreductase $(\boldsymbol{\Delta}), p$-nitrophenylphosphatase $(O)$, catalase $(\square)$ and succinate dehydrogenase $(\square)$ during growth of Crithidia fasciculata.

\section{Fractionation by differential centrifugation}

This procedure yielded a fraction PI that contained $10.8 \%$ of the total protein together with $101 \cdot 8 \%$ of the recovered units of succinate dehydrogenase (Table r). NADH:cytochrome $c$ oxidoreductase was distributed throughout the fractions, PI containing more $(40.9 \%)$ than the other three fractions. NADPH:cytochrome $c$ oxidoreductase was not detected in $\mathrm{P}_{3}$ and $\mathrm{S}_{3} ; \mathrm{PI}_{1}$ and $\mathrm{P}_{2}$ contained 24 and $\mathrm{I}_{4} \%$ of the activity respectively. Recoveries of this enzyme were always low in differential centrifugation experiments and this could be due to the partitioning of an essential cofactor by the fractionation procedure. Almost all the catalase activity $(98.4 \%)$ and $50 \%$ of the $p$-nitrophenylphosphatase activity were found in $\mathrm{S}_{3}$, the remainder of the activity of the latter being divided between the other three fractions. Protein and enzyme recoveries, except for NADPH:cytochrome $c$ oxidoreductase, were well within an acceptable margin of error for this procedure and gave an indication of the subcellular distribution of protein and of the enzymes studied. 
Table I. Distribution of marker enzymes in homogenates of Crithidia fasciculata after fractionation by differential centrifugation

\begin{tabular}{|c|c|c|c|c|c|c|}
\hline & $\begin{array}{c}\text { Whole } \\
\text { homogenate }\end{array}$ & PI & $\mathbf{P 2}$ & $\mathbf{P}_{3}$ & $\mathbf{S}_{3}$ & $\begin{array}{c}\text { Recovery } \\
(\%)\end{array}$ \\
\hline \multicolumn{7}{|l|}{ Protein } \\
\hline Concn (mg ml-1) & $5 \cdot 36$ & $\mathrm{I} \cdot 86$ & $I \cdot 04$ & $5 \cdot 84$ & 3.68 & \multirow[t]{3}{*}{ I I $7 \cdot 0$} \\
\hline Weight (mg) & 85.80 & $9 \cdot 30$ & $5 \cdot 20$ & $29 \cdot 20$ & $56 \cdot 70$ & \\
\hline$\%$ total & 100 & $10 \cdot 80$ & $6 \cdot 05$ & 33.90 & $66 \cdot 0$ & \\
\hline \multicolumn{7}{|l|}{$\begin{array}{l}\text { NADH: cytochrome } c \\
\text { oxidoreductase }\end{array}$} \\
\hline Specific activity & 54 & 214 & I $86 \cdot 5$ & $43 \cdot 7$ & $16 \cdot 2$ & \multirow[t]{3}{*}{$108 \cdot 5$} \\
\hline Activity (units) & 4635 & 1890 & 970 & 1270 & 915 & \\
\hline Activity (\% total) & 100 & $40 \cdot 9$ & $21 \cdot 0$ & $27 \cdot 6$ & $19 \cdot 8$ & \\
\hline \multicolumn{7}{|c|}{$\begin{array}{l}\text { NADPH: cytochrome } c \\
\text { oxidoreductase }\end{array}$} \\
\hline Specific activity & $43 \cdot 7$ & $95 \cdot 6$ & $93 \cdot 5$ & - & - & \multirow[t]{3}{*}{$38 \cdot 2$} \\
\hline Activity (units) & 3750 & 890 & 540 & - & - & \\
\hline Activity ( $\%$ total) & 100 & $23 \cdot 7$ & 14.4 & - & - & \\
\hline \multicolumn{7}{|c|}{ Succinate dehydrogenase } \\
\hline Specific activity & $1 \cdot 06$ & $10 \cdot 0$ & 0.68 & 0.25 & - & \multirow[t]{3}{*}{$113 \cdot 0$} \\
\hline Activity (units) & $9 I \cdot 3$ & $93 \cdot 0$ & $3 \cdot 57$ & $7 \cdot 15$ & - & \\
\hline Activity (\% total) & 100 & $\mathrm{IOI} \cdot 8$ & $3 \cdot 90$ & $7 \cdot 82$ & - & \\
\hline \multicolumn{7}{|l|}{ Catalase } \\
\hline Specific activity & 139 & 20.9 & $24 \cdot 9$ & $5 \cdot 76$ & 207 & \multirow[t]{3}{*}{$102 \cdot 3$} \\
\hline Activity (units) & 11900 & 194.5 & I 29.5 & $169 \cdot 5$ & II 700 & \\
\hline Activity ( $\%$ total) & 100 & $I \cdot 63$ & $\mathbf{I} \cdot 08$ & $\mathrm{I} \cdot 42$ & $98 \cdot 4$ & \\
\hline \multicolumn{7}{|c|}{ p-Nitrophenylphosphatase } \\
\hline Specific activity & $34 \cdot 4$ & $52 \cdot 5$ & $4 I \cdot 3$ & I $8 \cdot 80$ & $26 \cdot I$ & \multirow[t]{3}{*}{$92 \cdot 5$} \\
\hline Activity (units) & 2950 & 490 & 215.5 & 550 & 1475 & \\
\hline Activity ( $\%$ total) & 100 & $16 \cdot 6$ & $7 \cdot 60$ & 18.65 & $50 \cdot 0$ & \\
\hline
\end{tabular}

\section{Fractionation of a whole homogenate by high-speed zonal centrifugation}

After centrifuging whole homogenate for $165 \mathrm{~min}$ at $35000 \mathrm{rev} . \mathrm{min}^{-1}\left(6 \times 10^{6} \mathrm{~g}\right.$-min at the sample zone), analysis by light scattering at $260 \mathrm{~nm}$ revealed a complex distribution through the gradient, major peaks occurring at $\rho=\mathrm{I} \cdot \mathrm{II}$, probably due to ribosomal monomers, and at $\mathrm{r} \cdot 20$ (Fig. $2 a$ ). Protein analysis of the gradient showed that $56 \cdot 8 \%$ was sedimentable and could be detected up to $\rho=\mathrm{I} \cdot 22$; a major peak at $\rho=\mathrm{I} \cdot \mathrm{I}$ I corresponded to that of light scattering at $260 \mathrm{~nm}$ whilst the other major peak of protein $(25 \%$ of the total recovered) remained at the sample zone (Fig. 2a). NADPH:cytochrome $c$ oxidoreductase was distributed unevenly throughout the gradient and was $45 \%$ sedimentable; the bulk of the activity $(39 \%)$ remained at the sample zone (Fig. $2 b$ ). Malate dehydrogenase was also unevenly distributed throughout the gradient and $43 \%$ of the recovered activity remained at the sample zone. However, peaks of activity were noted at $\rho=\mathrm{I} \cdot \mathrm{I} 0, \mathrm{I} \cdot \mathrm{I} 5$ and $\mathrm{I} \cdot 2 \mathrm{I}$, the latter density probably marking the isopycnic density of mitochondria. $\beta$-Glucosidase was mainly soluble as $75 \%$ of the total activity remained at the sample zone. A large proportion (43\%) of the NADH:cytochrome $c$ oxidoreductase was recovered from the sample zone but $47.5 \%$ was sedimentable; a distinct peak of activity at $\rho=\mathrm{I} \cdot 20$ corresponded to the mitochondrial band (Fig. 2c). All the recovered catalase activity (approximately I00\%) was found in the sample zone, suggesting that this enzyme is soluble in C. fasciculata and has no peroxisomal association. The major peak of activity of $p$-nitrophenylphosphatase occurred at $\rho=\mathrm{I} \cdot 22$ with a distinct shoulder at $\rho=\mathrm{I} \cdot 20$ corresponding to the proposed 


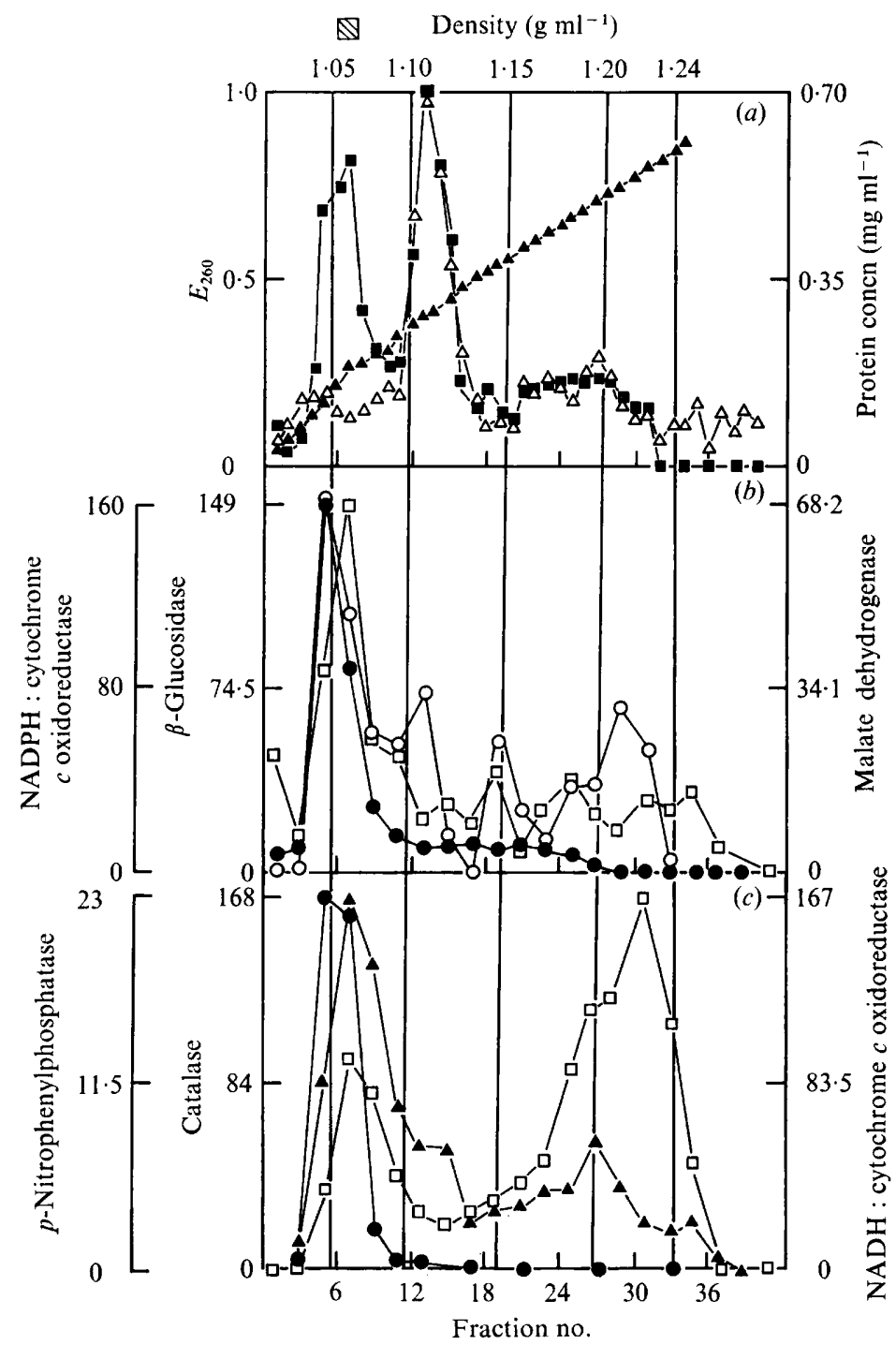

Fig. 2. High-speed subcellular fractionation of a whole homogenate of Crithidia fasciculata on a linear sucrose gradient in the MSE BXIV zonal rotor. Whole homogenate ( $14 \mathrm{ml}$ ), containing I $6.2 \mathrm{mg}$ protein, was loaded on to the gradient. The volumes of homogenate (diluted I in 20) and of fractions taken for assay were as follows: catalase, NADH: and NADPH:cytochrome $c$ oxidoreductases, $\beta$-glucosidase, $p$-nitrophenylphosphatase and malate dehydrogenase, all $0 \cdot 1 \mathrm{ml}$. Centrifugation was at $35000 \mathrm{rev}$. $\mathrm{min}^{-1}$ for $165 \mathrm{~min} .\left(6 \times 10^{6} \mathrm{~g}-\mathrm{min}\right.$ at the sample zone; $\int_{0}^{t} \omega^{2} . \mathrm{d} t=$ $\left.\mathrm{I} \cdot 45 \times 10^{11} \mathrm{rad}^{2} \mathrm{~s}^{-1}\right)$. The shaded rectangle represents the sample zone before centrifugation.

(a) Sucrose density gradient $(\Delta)$, light scattering at $260 \mathrm{~nm}$ after $\mathrm{I}$ in 30 dilution $(\triangle)$ and protein (घ); (b) NADPH:cytochrome $c$ oxidoreductase ( $\square$ ), malate dehydrogenase $(O)$ and $\beta$-glucosidase (O); (c) NADH:cytochrome $c$ oxidoreductase ( $\boldsymbol{\Delta})$, catalase (O) and $p$-nitrophenylphosphatase ( $\square)$. Specific activities of enzymes in the whole homogenate were as follows (recoveries in parentheses): NADPH: cytochrome $c$ oxidoreductase $57.7(24.8 \%)$; malate dehydrogenase, $79.5(75 \%)$; $\beta$-glucosidase, 5 . I (I $24 \%)$; NADH:cytochrome $c$ oxidoreductase, $63.2(25.2 \%)$; catalase, $5 \mathrm{I} \cdot 5$ (I $14 \%$ ); and $p$-nitrophenylphosphatase, 44.5 (58\%); protein recovery was $68 \%$. All enzyme activities are expressed as units $\mathrm{ml}^{-\mathbf{1}}$. 


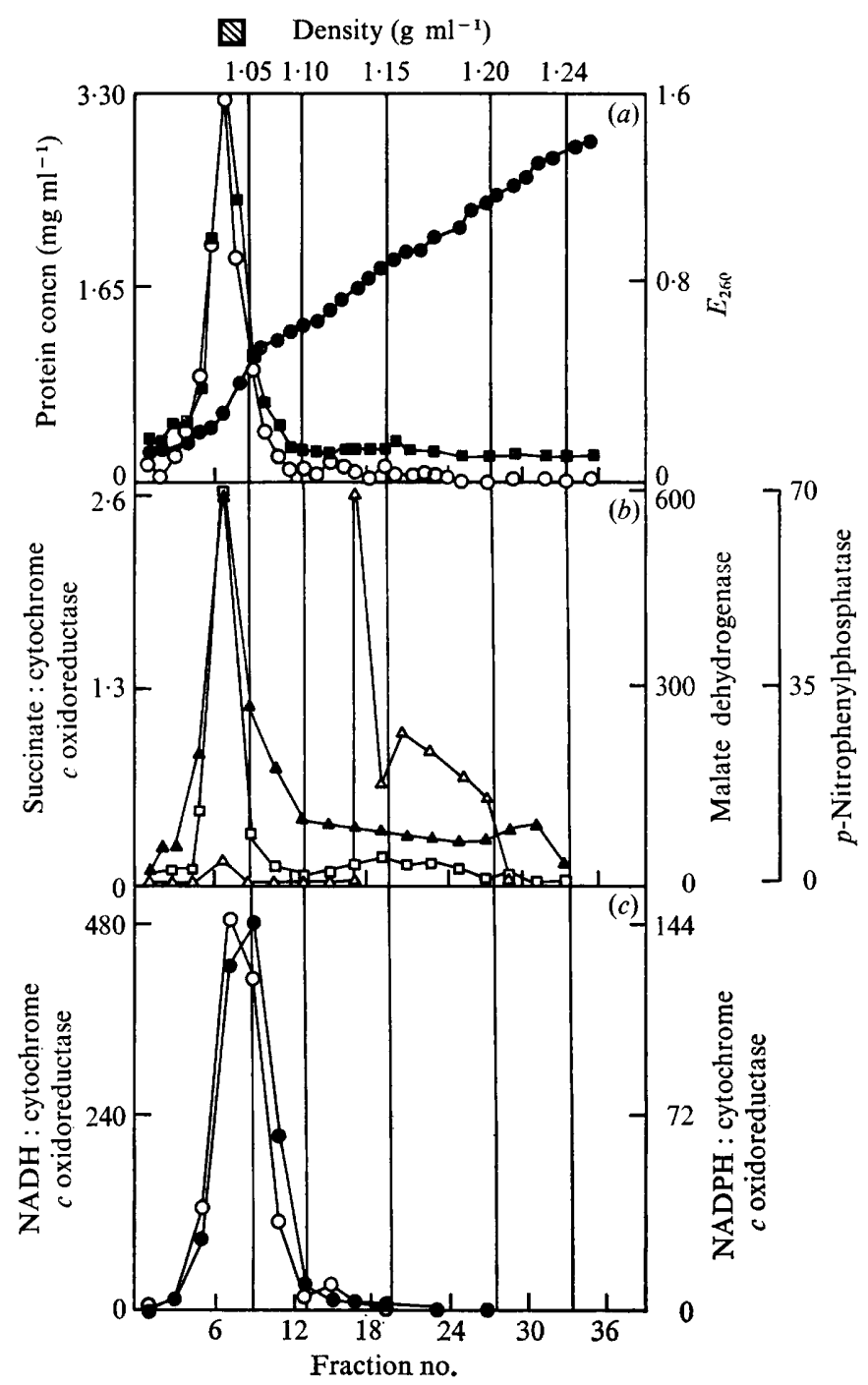

Fig. 3. Rate zonal separation of a whole homogenate of Crithidia fasciculata on a linear sucrose gradient in the MSE HS zonal rotor. The homogenate $(20 \mathrm{ml})$ contained $166 \mathrm{mg}$ protein. Whole homogenate was diluted $I$ in 20 and volumes of diluted homogenate and of fractions taken for assay were as follows: succinate:cytochrome $c$ oxidoreductase, malate dehydrogenase, $p$-nitrophenylphosphatase, NADH:cytochrome $c$ oxidoreductase and NADPH:cytochrome $c$ oxidoreductase, all $0.1 \mathrm{ml}$. After centrifuging at $10000 \mathrm{rev} . \mathrm{min}^{-1}$ for $30 \mathrm{~min}\left(\int_{0}^{t} \omega^{2} . \mathrm{d} t=2.25 \times 10^{\theta} \mathrm{rad}^{2}\right.$ $\mathrm{s}^{-1}$ ), fractions (10 $\mathrm{ml}$ ) were collected. The shaded rectangle represents the sample zone before centrifugation.

(a) Sucrose density gradient (O), light scattering at $260 \mathrm{~nm}$ after $\mathrm{I}$ in 30 dilution ( $\square$ ) and protein (O); (b) succinate: cytochrome $c$ oxidoreductase $(\triangle)$, malate dehydrogenase $(\square)$ and $p$-nitrophenylphosphatase $(\boldsymbol{\Delta}) ;(c)$ NADH:cytochrome $c$ oxidoreductase $(O)$ and NADPH:cytochrome $c$ oxidoreductase (O). Specific activities of enzymes in the whole homogenate were as follows (recoveries in parentheses): succinate:cytochrome $c$ oxidoreductase, $0.8(58.9 \%)$; malate dehydrogenase, I $20.8(76.5 \%) ; p$-nitrophenylphosphatase, 30.1 (83\%); NADH:cytochrome $c$ oxidoreductase, I $53 . \mathrm{I}(88.2 \%)$; and NADPH:cytochrome $c$ oxidoreductase, 59.9 (I48\%); protein recovery was $74.8 \%$. All enzyme activities are expressed as units $\mathrm{ml}^{-1}$. 
isopycnic density of mitochondria. This enzyme was $76 \cdot 4 \%$ sedimentable, only $20 \%$ of the total recovered activity remaining at the sample zone. Electron micrographs prepared from fractions I 3,18 and 28 indicated the increasing size of the various particles throughout the gradient. Fraction 28 contained structures up to I $\mu \mathrm{m}$ in diameter which showed characteristics of mitochondria, confirming the data obtained from enzymic analysis of this part of the gradient $(\rho=\mathrm{I} \cdot 2 \mathrm{r})$.

\section{Fractionation of a whole homogenate by rate zonal centrifugation}

Light scattering at $260 \mathrm{~nm}$ and protein show simple distributions, the main peaks for each occurring at the sample zone. Protein was only $16.9 \%$ sedimentable (Fig. $3 a$ ). Succinate:cytochrome $c$ oxidoreductase activity was $98.5 \%$ sedimentable; this enzyme, a mitochondrial marker, had a peak of activity at $\rho=\mathrm{I} \cdot \mathrm{I} 35$ (Fig. $3 b$ ). Malate dehydrogenase occurred mainly at the sample zone, but there was a second peak of activity at $\rho=\mathrm{I} \cdot \mathrm{I} 5$ corresponding to that observed for succinate:cytochrome $c$ oxidoreductase. The bulk of the $p$-nitrophenylphosphatase activity remained at the sample zone but $37 \%$ was sedimentable. A build-up of very large particles containing this enzyme is apparent at $\rho=\mathrm{I} \cdot 22$, corresponding to the major peak of this enzyme after high-speed zonal centrifugation (Fig. $2 c$ ). Both NADH: and NADPH:cytochrome $c$ oxidoreductases showed similar distributions, the bulk of the activity remaining at the sample zone. Electron micrographs prepared from fractions 2, 6, I I, I5, 19 and 23 showed a distinct gradation of particle size. Mitochondrial structures were evident only in fractions 19 and 23 and coincided with the wide band of succinate: cytochrome $c$ oxidoreductase activity (Fig. $3 b$ ). The mean diameter of the mitochondrial profiles in fraction 23 was $0.58 \pm 0.13 \mu \mathrm{m}$ (25 determinations).

\section{DISCUSSION}

Fractionation of extracts of the trypanosomatid Crithidia fasciculata produced by gentle disruption of digitonin-treated organisms suggests that there is good preservation of released organelles. Although microbodies have been observed by histochemical means in several Crithidia spp. (Müller, 1975), the present results confirm a previous observation (Cohen, 1972) that catalase in C. fasciculata is non-sedimentable and not associated with microbodies. Malate dehydrogenase is also primarily non-sedimentable, but a proportion of the activity is associated with mitochondria which sediment at $\rho=\mathrm{I} \cdot 20$ to $\mathrm{I} \cdot 2 \mathrm{I}$ on equilibrium density centrifugation. The presence of two distinct isoenzymes of malate dehydrogenase, one cytosolic and one mitochondrial, has been reported in C. fasciculata by Bacchi et al. (1964). Neither NADH: nor NADPH:cytochrome $c$ oxidoreductase could be assigned to a mitochondrial location; the low recoveries of these two enzymes from high-speed zonal centrifugation experiments suggest a progressive loss of activity which did not occur in rate zonal experiments due to the shorter centrifugation times and lower rotor speeds used. Good separation of $p$-nitrophenylphosphatase, a lysosomal marker, was achieved and this indicated the presence of lysosomal vacuoles sedimenting at approximately $\rho=\mathrm{I} \cdot 22$. A similar result has been obtained recently by McLaughlin, Meerovitch \& Injeyan (1976), who observed a band of $p$-nitrophenylphosphatase activity at $\rho=\mathrm{I} \cdot 22$ after high-speed zonal centrifugation of a homogenate of $C$. fasciculata for $\mathrm{I} 6 \mathrm{~h}$.

The results from the rate zonal centrifugation experiments indicate good separation of mitochondria as judged by the distribution of succinate:cytochrome $c$ oxidoreductase activity. The mitochondrial population moved well out of the sample zone; electron micrographs indicated a relatively homogeneous population with little contamination by 
membranes of non-mitochondrial origin. The lack of detectable NADH:cytochrome $c$ oxidoreductase in mitochondria-containing fractions was unexpected, as in other protozoa this enzyme system has a multi-locational distribution which includes mitochondria (Cooper \& Lloyd, 1972; Lloyd et al., 1971). Rate zonal experiments confirm that p-nitrophenylphosphatase is associated with large, rapidly sedimenting vacuoles, which can easily be separated from mitochondria. The observation that these organelles survive the procedure used for disruption of the organism confirms that the techniques reported here are suitable for further characterization of trypanosome organelles.

We thank Miss Susan Davies for skilled technical assistance. C. E. held a Science Research Council research studentship.

\section{REFERENCES}

Anderson, N. G., Waters, D. A., Fisher, W. D., Cline, G. B., Nunley, C. E., Elrod, L. M. \& Rankin, C. T. (1967). Analytical techniques for cell fractionations. V. Characteristics of the BXIV and BXV zonal centrifuge rotors. Analytical Biochemistry 21, 235-252.

Angelopoulos, E. (1970). Pellicular microtubules in the family trypanosomatidae. Journal of Protozoology I7, 39-5I.

Bacchi, C. J., Hutner, S. H., Ciaccio, E. I. \& Marcus, S. M. (1964). $\mathrm{O}_{2}$-polarographic studies on soluble and mitochondrial enzymes of Crithidia fasciculata glycerophosphate enzymes. Journal of Protozoology I5, 576-584.

CARTLEDGE, T. G. \& Lloyd, D. (1972). Subcellular fractionation by differential and zonal centrifugation of aerobically grown glucose-de-repressed Saccharomyces carlsbergensis. Biochemical Journal 126, 381-393.

CoHEN, L. A. (1972). Some ultrastructural, biochemical and physiological changes induced by the carcinogen 4-nitroquinoline- $\mathrm{N}$-oxide in the flagellate, Crithidia fasciculata. Ph.D. thesis, City University, New York.

COOPER, R. A. \& LLOYD, D. (1972). Subcellular fractionation of the colourless alga Polytomella caeca by differential and zonal centrifugation. Journal of General Microbiology 72, 59-70.

De Duve, C., BerThet, J. \& Beaufay, H. (1959). Gradient centrifugation of cell particles. Theory and applications. Progress in Biophysical Chemistry 9, 326-369.

EDWARDS, C. \& LLOYD, D. (1973). Terminal oxidases and carbon monoxide-reacting haemoproteins in the trypanosomatid, Crithidia fasciculata. Journal of General Microbiology 79, 275-284.

GaTr, S. (1969). $\beta$-Glucosidase from bovine brain. Methods in Enzymology XIV, I52-155.

HILL, G. C. \& WHITE, D. C. (1968). Respiratory pigments of Crithidia fasciculata. Journal of Bacteriology 95, $2151-2157$.

Kusel, J. P. \& STOREY, B. T. (1972). Evidence for the presence of two phosphorylation sites in mitochondria isolated from the trypanosomatid hemoflagellate, Crithidia fasciculata. Biochemical and Biophysical Research Communications 46, 50I-507.

Lloyd, D., Brightwell, R., Venables, S. E., ROACH, G. I. \& TURNer, G. (1971). Subcellular fractionation of Tetrahymena pyriformis ST by zonal centrifugation: changes in activities and distribution of enzymes during the growth cycle and on starvation. Journal of General Microbiology 65, 209-223.

Lowry, O. H., Rosebrough, N. J., FaRR, A. L. \& Randall, R. J. (I95I). Protein measurement with the Folin phenol reagent. Journal of Biological Chemistry 193, 265-275.

Mclaughlin, J., INJEYAN, H. A. \& MeEROVITCH, E. (I976). The subcellular distribution and properties of Crithidia sp. hydrolases with particular reference to pyrophosphate and orthophosphate monoester phosphohydrolases. Canadian Journal of Biochemistry 54, 365-381.

MüLLER, M. (1975). Biochemistry of protozoan microbodies: peroxisomes, $\alpha$-glycerophosphate oxidase bodies, hydrogenosomes. Annual Review of Microbiology 29, 467-483.

Poole, R. K. \& LLOYD, D. (1973). Oscillations of enzyme activities during the cell-cycle of a glucose-repressed fission yeast Schizosaccharomyces pombe 972h-. Biochemical Journal 136, 195-207.

Simpson, L. (1972). The kinetoplast of the hemoflagellates. International Review of Cytology 32, 139-207. TONER, J. T. \& WEBER, M. M. (1967). Oxidative phosphorylation in Crithidia fasciculata. Biochemical and Biophysical Research Communications 28, 82 I-826. 